\title{
Biology of Triatoma flavida Neiva, 1911 (Hemiptera: Reduviidae) under Laboratory Conditions
}

\author{
Daniel R Cabello ${ }^{+}$, Eliezer Lizano
}

Departamento de Biología, Facultad de Ciencias, Universidad de Los Andes, Mérida, 5101, Venezuela

The complete life cycle of Triatoma flavida, weekly fed on hens, was studied at $28 \pm 2^{\circ} \mathrm{C}$ and $80 \pm 10 \%$ $R H$. Aspects related to hatching, life span, mortality and feeding behavior for each stage of its life cycle were evaluated. The hatching rate observed for 100 eggs was $93 \%$ with an average incubation period of 27.2 days. Sixty-two nymphs completed the cycle and the mean egg to adult development time was 230.4 days. Mean duration of 1 st, 2nd, 3rd, 4th and 5th instar nymphs was 22.1, 25.3, 36.7, 49.7 and 69.4 days, respectively. The number of blood meals on each nymphal stage varied from 1 to 7 . The mortality rate was $6.5 \%$ for NI, 23\% for NIII and 7.5\% for NV nymphs. Mean number of laid eggs per female was 283.1. Adult survival rates were 344.8 \pm 256.4 days for males and $285.3 \pm 201.8$ days for females.

Key words: Triatoma flavida - population biology - Triatominae - life cycle

Triatoma flavida Neiva, 1911 has a restricted distribution in the countryside of Cuba, where it is the most abundant triatomine species (JiménezOzete \& Fuentes 1981). It has been found in human habitations (Lent \& Wygodzinsky 1979, JiménezOzete 1981), but there is no any record indicating that it actually colonizes in houses (Lent \& Wygodzinsky 1979). It is considered a sylvatic species that is eventually attracted to houses by lights (Jiménez-Ozete 1981). The natural host of this triatomine is not known with certainty, but there are indications that it is associated with the rodent Capromys pilorides (Lent \& Wygodzinsky 1979, Lent \& Jurberg 1981) and with dogs, pigs and the bat Artibeus jamaicensis (Jiménez-Ozete 1981).

Up to the present, the biology and natural history of this species is almost unknown, there is only some information on the duration of its life cycle under environmental temperature (Jiménez-Ozete 1981) and the biometry of the 1st instar nymphs (Jiménez-Ozete \& Fuentes 1981). As a part of a larger study on the comparative ecology of the genus Triatoma, the life cycle of $T$. flavida under experimental conditions is described for the first time.

\section{MATERIALS AND METHODS}

The population of $T$. flavida used in this experiment was obtained from a laboratory colony established in 1995 from triatomines captured in Cuba. The colony is maintained at the Institute

\footnotetext{
${ }^{+}$Corresponding author. Fax: 58-74-401286. E-mail: cabellod@ciens.ula.ve

Received 18 December 2000

Accepted 11 April 2001
}

Herman Lent of the University de Los Andes, Mérida, Venezuela, where bugs are kept at $26 \pm 3^{\circ} \mathrm{C}$ and $85 \pm 10 \% \mathrm{RH}$, and fed weekly on immobilized white leghorn hens.

The life cycle described in this work is based on a cohort constituted by 100 recently laid eggs ( 0 to $48 \mathrm{~h}$ old), these were kept in $150 \mathrm{~cm}^{3}$ glass containers until all viable eggs hatched. After hatching, all 1st instar nymphs were separated individually into plastic containers $(10.5 \mathrm{~cm}$ diameter x $20.5 \mathrm{~cm}$ height) lined with white filter paper and closed with cotton netting. Three days after egg hatching, the nymphs were individually offered a feed during a $3 \mathrm{~h}$ period each day until the first blood meal; after that they were offered a weekly feed. Specimens were maintained in a climatic chamber at $28 \pm 2^{\circ} \mathrm{C}$ and $80 \pm 10 \% \mathrm{RH}$, and were checked daily for ecdysis or death.

From the insects that completed development to the adult stage, 15 couples were placed in individual containers $(10.5 \mathrm{~cm}$ diameter x $20.5 \mathrm{~cm}$ height) and kept as indicated before to determine adult survivorship and oviposition patterns.

A partial life table analysis, following Southwood (1978) was developed for the cohort.

\section{RESULTS}

Egg hatching rate was $93 \%$ with an average incubation period of 27.2 days (range 21-32 days) (Table I). Sixty-two 5th instar nymphs completed development to adult ( 25 males and 37 females), taking an average of 3.0 blood meals per nymphal stage (range 1-7) (Table II). The mean egg to adult development time was 230.4 days (range 182 to 272 days). Adult survival ranged from 31 to 608 days for males (mean 344.8 \pm 256.4 ) and from 49 to 584 days for females (mean 285.3 \pm 201.8 ). Mean 
number of laid eggs per female was 283.1 (range 129-402).

Mortality showed an irregular pattern. There were no mortality in the molt from 2nd to 3rd and from 4th to 5th stages; the highest mortality rate was registered in the molt from 3rd to 4th stage (Table II).

The life table analysis indicated a net reproductive rate $(R o)$ of 104.7 times per generation under these conditions, with an instantaneous reproductive rate $(r)$ of 0.058 (Table III).

\section{TABLE I}

Egg to adult development cycle of Triatoma flavida fed weekly on hens

\begin{tabular}{lcccc}
\hline \multirow{2}{*}{ Stage } & & \multicolumn{3}{c}{ Duration in days } \\
\cline { 3 - 5 } & $\mathrm{N}$ & Min. & Max. & Mean \pm SD \\
\hline Egg-NI & 93 & 21 & 32 & $27.18 \pm 3.26$ \\
NI-NII & 87 & 19 & 32 & $22.11 \pm 2.41$ \\
NII-NIII & 87 & 23 & 40 & $25.29 \pm 3.01$ \\
NIII-NIV & 67 & 33 & 60 & $36.71 \pm 4.38$ \\
NIV-NV & 67 & 30 & 82 & $49.67 \pm 7.53$ \\
NV-AD & 62 & 62 & 87 & $69.40 \pm 7.19$ \\
\hline Total & 62 & 182 & 272 & $230.36 \pm 16.89$ \\
\hline
\end{tabular}

TABLE II

Number of blood meals and stage mortality for nymphal Triatoma flavida

\begin{tabular}{lccccc}
\hline Stage & & \multicolumn{3}{c}{ Number of blood meals } & \\
\cline { 3 - 5 } & $\mathrm{N}$ & Min. & Max. & Mean \pm SD & mortality \\
\hline I & 93 & 1 & 3 & $1.96 \pm 0.65$ & 6.4 \\
II & 87 & 1 & 3 & $2.07 \pm 0.38$ & 0 \\
III & 87 & 2 & 5 & $3.37 \pm 0.91$ & 22.9 \\
IV & 67 & 2 & 6 & $3.54 \pm 0.96$ & 0 \\
V & 67 & 3 & 7 & $3.79 \pm 1.07$ & 7.4 \\
\hline
\end{tabular}

\section{TABLE III}

Partial stage specific life table for Triatoma flavida (notation following Southwood 1978)

\begin{tabular}{lrr}
\hline Stage & $l x$ & $d x$ \\
\hline Egg & 100 & 7 \\
I & 93 & 6 \\
II & 87 & 0 \\
III & 87 & 20 \\
IV & 67 & 0 \\
V & 67 & 5 \\
Adult & 62 & 62 \\
\hline
\end{tabular}

\footnotetext{
Number of females produced by cohort

$R_{o}=\frac{\mathrm{x} \text { mean eggs laid per female }}{\text { number of eggs beginning cohort }}=104.7$

$r=\log \left(R_{o}\right) /$ egg-to-egg generation time $=0.058$

$l x=$ number entering stage $x$

$d x=$ number dying in stage $x$
}

\section{DISCUSSION}

The development cycle of triatomines is different according to species and environmental conditions, and is deeply influenced by the accessibility of adequate blood sources (Schofield 1985). Biological data are available for many species, however comparisons among studies are difficult due to large differences in experimental design, particularly with respect to temperature, humidity, feeding frequency, blood meal sources, density of insects per container, number and stage of specimens, and frequency of observations (Zárate 1983).

In this work, rearing conditions were optimized with absence of intra-specific competition during their development. Under these conditions, mean development time of $T$. flavida (230.4 \pm 16.9 days) was longer than most species of Triatoma. So Rabinovich (1972) registered an average development time of 141 days for $T$. infestans fed weekly on hens, and kept at $26 \pm 11^{\circ} \mathrm{C}$ and $60 \pm 10 \% \mathrm{RH}$. Feliciangeli and Rabinovich (1985) found a life cycle of 178.9 days in $T$. maculata kept at $28 \pm 1^{\circ} \mathrm{C}$, $60 \pm 10 \%$ rh and fed weekly on hens. Braga et al. (1998) indicated that the life cycle of T. rubrofasciata fed on Swiss mice varied between 83-246 days (at $29^{\circ} \mathrm{C}, 80 \% \mathrm{RH}$ ) and $115-677$ days (at 20.5 to $33^{\circ} \mathrm{C}, 91.3 \pm 4.3 \% \mathrm{RH}$ ). Martínez-Ibarra and Katthain-Duchateau (1999) reported a life cycle of $168.0 \pm 11.7$ days in $T$. pallidipennis fed every three days on hens. Few studies on species of Triatoma have showed life cycles longer than this one; for example, Zeledón et al. (1970) observed a life cycle ranging from 257 to 411 days (mean: $320-330$ days) at room temperature $\left(22.8-24.4^{\circ} \mathrm{C}\right)$ and from 180 to 336 days (mean: $233-275$ days) at $26.5^{\circ} \mathrm{C}$ for $T$. dimidiata fed on rabbits; and Mena-Segura et al. (1994) indicated for T. pallidipennis, fed every 1012 days on hens, a mean duration of the life cycle of 411 days (range 261-581 days).

It seems evident from the data on the life cycle of $T$. flavida that in general, there is an increase in time between molts as the insect grows. This is in agreement with the data from the literature for the life cycle of other species of Triatoma (Lucena 1960, Zeledón et al. 1970, Jiménez-Ozete 1981, Zárate 1983, Feliciangeli \& Rabinovich 1985, Martínez-Ibarra \& Katthain-Duchateau 1999).

Among triatomine species molting takes place on a range of days, even for groups of insects fed to repletion simultaneously. For any species, the range from first to last molt increases with age, decreases with rising temperature, and varies greatly with blood source (Zeledón et al. 1970). For T. flavida, the ranges of molting from first to last individual were very long in all instars, in spite of the abundant occasions to feed, suggesting that factors as 
well as physiologic variation could be implicated. Such factors might include individual rates of feeding, behavioral responses to the environment during feeding or to the host animal itself.

The average incubation period, $27.2 \pm 3.3$ days was very close to the registered by Jiménez-Ozete (1981) with T. flavida (28.7 \pm 0.3 days) in the summer months (at $30^{\circ} \mathrm{C}$ ) and higher than that found $\left(21.0 \pm 0.4\right.$ days) in the winter months $\left(\right.$ at $\left.24^{\circ} \mathrm{C}\right)$ in Cuba. In other species of Triatoma the mean duration of the egg stage ranges between 17 and 29 days, so our results are one of the longest for Triatoma species.

Egg hatching rates in Triatoma species also vary. They are usually above $80 \%$ (Zeledón et al. 1970, Rabinovich 1972, Feliciangeli \& Rabinovich 1985, Braga et al. 1998), although lower average hatch rates of $61.9 \%$ (Mena-Segura et al. 1994) and $60 \%$ (Martínez-Ibarra \& Katthain-Duchateau 1999) have been recorded in colonies of $T$. pallidipennis. The $93 \%$ hatch rate showed here may reflect the good conditions in which the colony is kept in our laboratory.

The irregular pattern registered in the mortality rate was similar to those observed in other Triatoma species. The lowest mortality rate is often in the molt from third to fourth or from 4th to 5th stages (Zeledón et al. 1970, Rabinovich 1972, Feliciangeli \& Rabinovich 1985, Martínez-Ibarra \& Katthain-Duchateau 1999) and it is occasionally detected in the first molting (Mena-Segura et al. 1994, Braga et al. 1998). In the youngest nymphs, mortality seems to be due to failure to feed, since dead insects were usually without significant intestinal contents. On the contrary, mortality in the oldest nymphs came about essentially in the course of their molting.

The development time and the high reproductive rate could represent close to the maximum achievable for this species under optimum conditions. The calculated net reproductive rate $\left(R_{0}\right)$ was considerably higher than those determined for $T$. infestans: 25.04 (Rabinovich 1972) and for $T$. maculata: 86.2 (Feliciangeli \& Rabinovich 1985); although lower than the registered for $T$. pallidipennis (Martínez-Ibarra \& KatthainDuchateau 1999).

\section{ACKNOWLEDGMENTS}

To Dr CJ Schofield and the anonymous reviewer whose suggestions improved the original manuscript.

\section{REFERENCES}

Braga MV, Pinto ZT, Lima MM 1998. Life cycle and reproductive patterns of Tiatoma rubrofasciata (De Geer, 1773) (Hemiptera: Reduviidae), under laboratory conditions. Mem Inst Oswaldo Cruz 93: 539542.

Feliciangeli MD, Rabinovich J 1985. Vital statistics of Triatominae (Hemiptera: Reduviidae) under laboratory conditions. II. Triatoma maculata. J Med Entomol 22: 43-48.

Jiménez-Ozete H 1981. Observaciones sobre la biología de Triatoma flavida Neiva, 1911 en Cuba. Rev Cub Med Trop 33: 42-50.

Jiménez-Ozete H, Fuentes O 1981. Triatoma flavida (Hemiptera: Reduviidae). I. Estudio biométrico de larvas. Rev Cub Med Trop 33: 195-200.

Lent H, Wygodzinsky P 1979. Revision of the Triatominae (Hemiptera: Reduviidae), and their significance as vectors of Chagas' disease. Bull Am Mus Nat Hist 163: 123-520.

Lent H, Jurberg J 1981. As espécies insulares de Cuba do gênero Triatoma Laporte (Hemiptera: Reduviidae). Rev Brasil Biol 41: 431-439.

Lucena DT 1960. Evolução do Triatoma brasiliensis Neiva, 1911, no laboratório. Rev Brasil Biol 20: 295302.

Martínez-Ibarra JA, Katthain-Duchateau G 1999. Biology of Triatoma pallidipennis (Stal, 1872) (Hemiptera: Reduviidae: Triatominae) under laboratory conditions. Mem Inst Oswaldo Cruz 94: 837-840.

Mena-Segura C, Carcavallo RU, Galíndez-Girón I, Canale D1994. Ciclo de vida de Triatoma pallidipennis (Stal, 1872) (Hemiptera: Reduviidae: Triatominae). Entomol Vect 1: 33-38.

Rabinovich JE 1972. Vital statistics of Triatominae (Hemiptera: Reduviidae) under laboratory conditions. I. Triatoma infestans Klug. J Med Ent 9: 351-370.

Schofield CJ 1985. Population dynamics and control of Triatoma infestans. Ann Soc Belge de Méd Trop 65 (Suppl. 1): 149-164.

Southwood TRE 1978. Ecological Methods with Particular Reference to the Study of Insect Populations, 2nd ed., Chapman \& Hall, London, 524 pp.

Zárate LG 1983. The biology and behavior of Triatoma barberi (Hemiptera: Reduviidae) in Mexico. III. Completion of the life cycle, adult longevity and egg production under optimal feeding conditions. J Med Entomol 20: 485-497.

Zeledón R, Guardia VM, Zúñiga A, Swartzwelder JC 1970. Biology and ethology of Triatoma dimidiata (Latreille, 1811). I. Life cycle, amount of blood ingested, resistance to starvation, and size of adults. $J$ Med Entomol 7: 313-319. 